\title{
Google Arts \& Culture y los museos virtuales: nuevas herramientas de difusión del patrimonio cultural
}

\section{Clara Reigosa Lombao}

${ }^{a}$ Máster en Estudios Avanzados en Museos y Patrimonio Histórico-Artístico (Universidad Complutense de Madrid), C/Profesor Aranguren S/N, 28040 Madrid, clarareigosalombao@gmail.com

\begin{abstract}
Resumen
A medida que la sociedad evoluciona la interpretación de los museos, monumentos o los sitios del patrimonio natural y cultural, se ha transformado a favor de una mayor y mejor comunicación con los diferentes públicos. Alejadas en el tiempo se encuentran las corrientes de pensamiento que obstaculizan la comprensión y disfrute de estos espacios por parte de una élite cultural. La llegada de las nuevas tecnologías y la implantación de estas en museos ha supuesto un gran avance en el campo de la difusión patrimonial.

Entre la multitud de opciones que encontramos en la web, y tras muchos años de trabajo, mejora y optimización, Google Arts \& Culture se presenta como una de las grandes herramientas para el conocimiento online del patrimonio cultural español. Esta iniciativa, nacida en España en el año 2009, fusiona las tecnologías marca Google con el interés de los museos y sitios patrimoniales por estar en la red; es decir, por tener un hueco en el mundo.
\end{abstract}

Palabras clave: Google Arts \& Culture, museos virtuales, tecnología, difusión cultural, museología.

\begin{abstract}
As society evolves, the interpretation of museums, monuments or natural and cultural heritage sites has transformed in favour of greater and better communication with different audiences. Far removed in time are the currents of thought that hinder the understanding and enjoyment of these spaces by a cultural elite. The arrival of new technologies and their implementation in museums has meant a great advance in the field of heritage dissemination.

Among the multitude of options that we find on the web, and after many years of work, improvement and optimization, Google Arts \& Culture is presented as one of the great tools for online knowledge of Spanish cultural heritage. This initiative, born in Spain in 2009, merges Google's trademark technologies with the interest of museums and heritage sites in being on the web; in other words, in having a place in the world.
\end{abstract}

Keywords: Google Arts \& Culture, virtual museum, technology, cultural promotion, museology. 


\section{Introducción}

A finales de los años 40 del siglo pasado, André Malraux planteó la idea del Museo Imaginario. En líneas generales, esta idea se basaba en que los museos daban una visión limitada del arte y de los artistas, debido a la colección y al espacio del museo. Para él, el museo ideal sería el museo imaginario, aquel creado en nuestra mente, porque nuestros conocimientos van más allá de las paredes del museo (Malraux, 2017/1965). Para materializar esta idea, Malraux utilizaba reproducciones fotográficas de las obras, y las extendía en el suelo para distribuirlas y contemplarlas a su gusto, de manera libre y autónoma.

Esta idea de Malraux es muy interesante porque coloca al individuo en una posición de mayor libertad y accesibilidad al museo y a las obras de arte. Este es el concepto que me ha llevado a plantear esta ponencia, viajando en el tiempo y trasladando este concepto a la actualidad, y me pregunto si los museos virtuales, en concreto Google Arts \& Culture, no son más que una evolución de esta idea, de libre acceso y contemplación al arte. ¿Es Google Arts \& Culture una nueva herramienta para una vieja problemática?

A raíz de esto, decidí plantear este estudio en dos partes. En la primera, se analizará qué es Google Arts, en qué marco teórico se inserta, dentro de los denominados museos virtuales; en la segunda, de carácter práctico, se realizará un análisis de uso de la plataforma, para entender cómo funciona y analizar un caso paradigmático de museo virtual.

\section{Los museos e Internet: una evolución constante}

En primer lugar, hay que entender la llegada de los museos virtuales como la suma de varios factores. Los museos van cambiando sus funciones a medida que la sociedad se transforma, así a finales del siglo pasado comienza a crearse una nueva sociedad derivada de la globalización y la democratización social. Esto se aprecia en las nuevas museologías que colocan al público como elemento principal del museo; las dos últimas definiciones del ICOM (1974 y 2007) ya incluyen entre las funciones de esta institución, comunicar o transmitir la información al público. Si a todo esto le sumamos la aparición de las nuevas tecnologías desde finales del siglo XX, ya tenemos el punto de partida para la aparición de los museos virtuales.

De todas formas, la llegada de los museos virtuales no se produce en el momento en que los museos y las nuevas tecnologías, especialmente Internet, se encuentran. Existen diferentes páginas web de museos en función de cómo se muestra el contenido museal en la red. En primer lugar, encontramos las páginas web más simples, donde solo se muestra la información esencial para realizar una visita presencial, son los denominados folletos electrónicos (Carreras, 2005), como la página web del Museo Provincial de Lugo. En segundo lugar están las páginas webs de museos, como la del Museo de Bellas Artes de A Coruña, donde además de la información esencial, también se puede consultar algunas obras de la colección. En un tercer nivel estarían los museos que diferencian el contenido que se muestra según el sector de edad que visite la web, esto ocurre en la página del Museo Nacional Centro de Arte Reina Sofía (MNCARS) (Santacana y Hernández, 2006). Finalmente, en la última fase estarían los museos virtuales, aquellos que ofrecen al público un contenido que va más allá de las paredes del museo, donde no solo se ofrece información, sino que también se crean relaciones digitales con otros museos y obras (Schweibenz, 2004).

\section{1. ¿Qué es un museo virtual?}

Definir qué es un museo virtual es algo complejo, teniendo en cuenta que el Consejo Internacional de Museos (ICOM) no ha ofrecido ninguna definición de este término. Pero no sólo no existe una definición independiente, sino que ninguna de las últimas definiciones de la palabra "museo" -se corresponden con los años 1974 y 2007- hablan sobre esta nueva tipología. Los museos virtuales se alzan como esos nuevos espacios que todos conocen y muchos utilizan, sin un sustento teórico esencial para que sean respetados por los profesionales del sector y por el público genérico.

En este sentido, en septiembre de 2019 el ICOM hacía pública una nueva definición de museo en la que llevaba varios años trabajando. Muchos museólogos concebían esta como una nueva oportunidad para incorporar a la definición los nuevos paradigmas de museos, entre los que se encontrarían los museos virtuales. Sin embargo, la nueva definición, que finalmente no fue aprobada, volvía a carecer de una mención hacia estas nuevas tipologías. De momento, tendremos 


\section{Reigosa Lombao}

que esperar a una nueva corrección y publicación de la definición de museo, aunque todo parece indicar que no habrá, de nuevo, una consideración a estas colecciones en red.

Para entender qué es un museo virtual, es necesario recurrir a las definiciones que diversos autores han dado sobre estos museos. Guiándonos por las definiciones de Deloche (2001), Talens y Hernández (1997), Mckenzie (1997) y Colorado (1997), podemos entender los museos virtuales como un conjunto de objetos digitalizados, que se pueden contemplar desde cualquier parte del mundo, y con los que se puede interactuar de manera personal y libre. Siguiendo estos parámetros, Google Arts \& Culture es un museo virtual.

Dos de los factores claves de estos nuevos museos, el trabajo con copias digitalizadas de objetos reales y su contemplación desde cualquier parte del mundo, son fundamentales para entender que los museos virtuales no tienen las mismas funciones que los museos tangibles. Mientras que los segundos trabajan con objetos reales, los primeros utilizan imágenes que se pueden observar a través de una pantalla. Es por esto que los museos virtuales deben entenderse como un complemento a los museos tangibles, pero nunca como un sustituto; deben ser un incentivo para la visita real, un espacio que hace de los museos espacios más accesibles, con múltiples posibilidades de contemplación; y un espacio de difusión para el museo y su colección.

\subsubsection{La accesibilidad como ventaja de los museos virtuales}

Entendiendo estos espacios como complementos de los museos tangibles, podemos entender que sus características diferenciadoras generan muchas ventajas para los diferentes tipos de públicos. En líneas generales, podemos hablar de que los museos virtuales generan una gran accesibilidad a los museos y a las obras de arte. Esto, en cierto modo, nos llevaría a hablar de que los museos virtuales gozan de una serie de ventajas sobre los museos tangibles; sin embargo, si entendemos los museos virtuales como un añadido al museo real, y no como un sustituto, no existirían ventajas y desventajas de un tipo de museo sobre el otro, sino que ambos forman un todo que únicamente genera beneficios al visitante.

Los museos virtuales son más accesibles, principalmente, porque permiten un acceso continuado a la colección, las 24 horas del día, siempre que se tenga una conexión a internet (Moreno, 2005). Gracias a esta ubicuidad, se rompen las barreras geográficas, que pueden ser de dos tipos. Se eliminan las barreras geográficas de las instituciones que, independientemente de en qué espacio físico se encuentren, todas están en el mismo punto de partida, la red. Por otra parte, se rompen las barreras geográficas de los visitantes que, de igual forma que las instituciones, no importa en que parte del territorio se encuentren, pueden acceder al mismo contenido a través de un ordenador.

Además, los museos virtuales rompen las barreras físicas del museo. Se rompe cualquier barrera física que impida la visita a personas con algún tipo de discapacidad física o intelectual, ya que este tipo de museos permiten la contemplación desde casa y en solitario. Además, en el caso de Google Arts \& Culture, existen múltiples mecanismos que permiten acercarse a la obra, algo que en un museo tangible sería impensable. Pero también se rompe cualquier barrera física que tenga el museo por razones museográficas. En los museos virtuales se puede mostrar cualquier obra aunque el museo esté cerrado, aunque alguna de las obras haya salido del museo por un préstamo temporal o aunque alguna de ellas esté en proceso de estudio o restauración. Sin un museo virtual como Google Arts \& Culture sería imposible visitar el Altar de Pérgamo, en el museo homónimo de Berlín, que lleva desde el año 2014 en proceso de restauración (Doncel, 2014).

Por último y, quizá lo más importante, los museos virtuales generan al visitante una libertad que no se tiene en ningún otro museo. Mientras que nuestra visión de los museos tangibles está condicionada por el discurso museológico que el conservador haya escogido para ese momento, o por los planteamientos generales del museo en cuestión, en los museos virtuales es el propio visitante el que escoge cómo observar y disfrutar de la colección. No existe ninguna autoridad museológica que indique cómo hay que ver el museo, es el visitante virtual el que elige a qué bienes acceder y cómo acceder a ellos (Carreras, 2005). 


\section{Google Arts \& Culture. Un caso paradigmático de museo virtual}

La aparición de Google Arts \& Culture como museo virtual es interesante por diversos motivos. Primero, porque este proyecto no nació con la idea preconcebida de ser un museo virtual, sino que se desarrolló a partir de una idea más básica de contemplación de una serie de obras en un museo aislado. Y, además, porque su génesis está vinculado a un proyecto personal y local de la compañía americana. Google Arts \& Culture nació entre los años 2008 y 2009 en España, gracias al proyecto de una trabajadora de la compañía, Clara Rivera, que dedicó parte de su tiempo en pensar un proyecto que hiciera más accesible el arte y los museos. Decidió comenzar este trabajo con una colaboración con el Museo Nacional del Prado, lo que en su momento se denominó "Obras Maestras del Prado en Google Earth". Este proyecto comenzó en esta web de mapas, en la que se creó una capa especial dedicada al Museo del Prado donde se podían contemplar 14 obras del museo en alta resolución (Rivera, 2009).

Esta unión generó mucha curiosidad entre los espectadores, lo que motivó la mejora y ampliación del proyecto. Así, en el año 2011 Google presentó "Google Art Project", una plataforma web basada en el experimento con el Prado pero, esta vez, de escala mundial. El Museo del Prado decidió no incorporarse a esta plataforma, pero importantes museos de todo el mundo vieron esto como una oportunidad para introducirse en el mundo digital (Modenessi, 2011).

Este proyecto continuó creciendo en el tiempo, a medida que se incorporaban nuevos museos, Google creaba nuevas plataformas que seguían teniendo como objetivo la difusión del patrimonio cultural, como la web Google Cultural Institute o la herramienta "Momentos Históricos". Todas estas plataformas, acabaron reformulándose en una sola en julio de 2016, en lo que hoy se conoce como Google Arts \& Culture.

En la actualidad, Google Arts \& Culture cuenta con más de 2.000 instituciones culturales, tiene alrededor de 6 millones de imágenes en red, y más de 6.000 exposiciones en la web. La finalidad de Google con este proyecto es democratizar el acceso al arte y a la cultura. Para esta democratización, Google ofrece un acceso gratuito a la web, con la única condición de disponer de un ordenador y una conexión a internet. Pero además, para que el acceso sea verdaderamente democrático no solo se necesita que el proyecto tenga un coste 0 para el usuario, sino que también se debe democratizar el acceso de manera que sea dinámico y permita que todo el mundo, independientemente de sus conocimientos sobre arte, puedan disfrutar y entender la obra. Para esto, Google propone una serie de herramientas (Tabla 1), desde las más sencillas como filtros de búsqueda, hasta herramientas tecnológicas más complejas (Street View o imágenes con Art Camera), o incluso contenido elaborado (temas y reportajes).

Tabla 1. Herramientas para acceder al contenido cultural de Google Arts \& Culture

\begin{tabular}{|c|c|c|}
\hline $\begin{array}{c}\text { Filtros para explorar los elementos } \\
\text { digitalizados }\end{array}$ & \multicolumn{2}{|c|}{$\begin{array}{l}\text { - Colecciones } \\
\text { - Artistas } \\
\text { - Técnicas artísticas } \\
\text { - Corrientes artísticas } \\
\text { - Acontecimientos históricos } \\
\text { - Personajes históricos } \\
\text { - Lugares del mundo } \\
\end{array}$} \\
\hline & \multicolumn{2}{|c|}{$\begin{array}{l}\text { - Imágenes con Art Camera } \\
\text { - Recorridos virtuales por museos y lugares patrimoniales gracias } \\
\text { a Street View. } \\
\text { - Vídeos en } 360^{\circ}\end{array}$} \\
\hline $\begin{array}{l}\text { Herramientas tecnológicas para } \\
\text { explorar los elementos digitalizados }\end{array}$ & - Experimentos & $\begin{array}{l}\text { - Art Palette } \\
\text { - Bagan } \\
\text { - Life Tags } \\
\text { - MoMa \& Machine Learning } \\
\text { - X Degrees of Separation } \\
\text { - T-SNE Map } \\
\text { - Free Fall } \\
\text { - Curator Table } \\
\text { - } \text { Xags } \\
\end{array}$ \\
\hline Contenido elaborado & \multicolumn{2}{|c|}{$\begin{array}{ll} & \text { Temas } \\
\text { - } & \text { Reportajes (exposiciones y editoriales) } \\
\end{array}$} \\
\hline
\end{tabular}

Fuente: Elaboración propia (2019) 


\section{Reigosa Lombao}

Sin embargo, también es necesario hablar de los puntos negativos que tiene Google Arts \& Culture o, más bien, de los aspectos a tener en cuenta para que no utilicemos este museo virtual de manera incorrecta. En primer lugar, hay que entender que Google Arts \& Culture tan solo contempla una pequeña parte de los museos y las obras de arte que hay en el mundo. Google Arts no puede funcionar como buscador universal, ya que hay gran cantidad de artistas, obras o museos que no forman parte de él. Por ejemplo, apenas hay en la plataforma obras de Pablo Picasso, ya que la empresa americana no tiene sus derechos de reproducción.

Además, este museo virtual debe considerarse un proyecto visual, que trabaja fundamentalmente con imágenes, a las que intenta sacar su máximo partido. Exceptuando los temas y reportajes, que realizan las propias instituciones adheridas, el peso de la compañía se centra en la experiencia sensorial del visitante. Google no aporta ningún tipo de contenido escrito de carácter formativo y las descripciones que aporta en cada artista, corriente, técnica artística, colección, personajes o acontecimiento histórico se toman de wikipedia. Debemos enmarcar esta plataforma como soporte tecnológico para dar difusión y accesibilidad a los museos e instituciones culturales, y no como una fuente bibliográfica para estudios académicos.

\subsection{Utilización y aprovechamiento de la plataforma}

Para entender el uso de la plataforma, hemos decidido realizar una encuesta enfocada a los dos sectores que utilizan la web, las instituciones culturales y los usuarios, en el marco territorial del Estado español. En España, eran 103 las instituciones culturales que estaban adheridas a Google Arts \& Culture en el momento de realizar la encuesta (marzoabril 2018). De ellas, recibí la respuesta de 35. Por otro lado, realicé la encuesta a 241 usuarios. A las instituciones se les ha preguntado sobre la gestión del contenido que proporcionaban a la web, y a los usuarios sobre el conocimiento y uso de la plataforma.

En relación a las instituciones, más de la mitad (54,3\%) ha decidido incorporarse a Google Arts \& Culture con el fin de difundir el contenido de su colección. Entre el resto de motivos, destacan el interés por crear una colección virtual y el acercamiento de la colección a nuevos visitantes.

En contraposición al interés mostrado en la divulgación, la gestión del contenido de la web está muy polarizada. En el $44,2 \%$ de los casos, es el departamento de difusión y comunicación el encargado de esta tarea, mientras que en el 55,8\% restante no hay una respuesta unánime. Hay hasta 7 departamentos diferentes encargados de Google Arts \& Culture (difusión, documentación, conservación y restauración, exposiciones, investigación, educación y publicaciones).

Posiblemente, derivado de este problema de asignación de tareas, se comprenden los resultados de la actualización del contenido. El 85,7\% de las instituciones encuestadas actualiza el contenido una vez al año o ninguna, llama la atención que las instituciones más grandes (entre 500.000 y 1 millón de visitas anualmente) son las que menos lo actualizan, el $64,2 \%$ de ellas lo hacen menos de una vez al año.

A pesar de que no son muchos los recursos dedicados a la actualización, la nota media que dan las instituciones a la utilidad de la herramienta es de un 7,1 sobre 10. Por último cabe destacar que, tras la adhesión a Google Arts \& Culture, las instituciones no aprecian un impacto significativo en el número de visitantes, ni en la página web de la institución, ni en el propio museo.

En cuanto a los usuarios, la mayoría de personas encuestadas no conocía Google Arts \& Culture (74,2\%). Tras explicarles el funcionamiento de la plataforma, al $98 \%$ les parecía una idea interesante, y un $88,5 \%$ querría descubrir lo que le ofrece la página web. Estos datos son muy reveladores acerca del todavía inexplorado potencial de la herramienta, ya que suscita un gran interés entre los usuarios no conocedores.

De las personas que sí conocen la herramienta, el 47,5\% la ha descubierto a través de un conocido. Esto, sumado al alto porcentaje de desconocimiento, puede deberse a un fallo en la gestión de las instituciones, ya que tan solo en 13 de ellas encontramos un enlace directo a Google Arts desde la página principal de su propia página web.

Entre las personas que sí la conocen, la mayoría $(65,5 \%)$ la visita de manera esporádica. Los dos principales motivos para consultar la web son el entretenimiento y el aprendizaje. Además, la herramienta más utilizada es la Art Cameraconviene recordar que esta fue la idea con la que comenzó el proyecto en el Museo del Prado, y 9 años después sigue 
suscitando expectación-. Los Experimentos son la herramienta menos utilizada, probablemente, por su funcionamiento más complejo a la hora de ponerlos en marcha.

Entre los usuarios que sí conocen la herramienta, un 80,3\% consideran Google Arts una buena forma de conocer un museo, pero no como sustitutivo de una visita presencial, ya que el $84,3 \%$ no cree que este tipo de plataformas reduzcan el público tradicional de las instituciones. Esto concuerda con la finalidad que Google le quiere dar a la plataforma, que esta sirva complemento a las visitas y no como una alternativa a la visita real.

De estas encuestas se han sacado dos conclusiones. Por parte de las instituciones, existe una falta de atención generalizada a la plataforma. Cada vez se adhieren más museos a la web pero, una vez dentro, no actualizan el contenido que ofrecen. Por parte de los usuarios, hay un gran desconocimiento general de este museo virtual, probablemente ligado a lo anterior, si las instituciones no atienden, actualizan o patrocinan su inclusión, no dan opción a que se conozca.

\section{Conclusiones}

Retomando la idea inicial, Malraux materializaba su museo imaginario con reproducciones fotográficas, hoy en día se puede hacer lo mismos desde el ordenador de nuestra casa, con la red como espacio ilimitado. Hace casi 80 años que se planteaba esta idea que, como vemos, se traslada a la actualidad. El título de esta ponencia utilizaba una pregunta para que nos cuestionemos si los museos virtuales son tan vanguardistas y rompedores como creemos, o si son solo una continuación de una idea simple, la libertad del visitante para acceder a un museo.

Seguramente Malraux no planteaba su teoría como base para una mayor accesibilidad a los museos, porque entonces estos no estaban enfocados al gran público. Pero su idea predice la manera en la que ahora comprendemos o queremos comprender los museos: no existe un perfil único de visitante, no existe un recorrido único, no existe una masa de personas con las mismas capacidades, sino que todos somos distintos y todos tenemos derecho a acceder a los museos, como espacios que albergan una memoria colectiva.

\section{Referencias}

Carreras, C. (2005). Museos enredados. Nuevos dilemas, nuevos horizontes en internet. En C. Carreras (Ed.), Patrimonio cultural y tecnologías de la información y la comunicación (pp. 161-182). Cartagena: Concejalía de Cultura de Cartagena.

Colorado, A. (1997). Hipercultura visual. El reto hipermedia en el arte y la educación. Madrid: Complutense.

Deloche, B. (2002). El Museo Virtual: hacia una ética de las nuevas imágenes. Gijón: Trea.

Doncel, L. (2014, 29 de septiembre). Despedida del Altar de Pérgamo. En El País. Recuperado de: https:// elpais.com/cultura/2014/09/29/actualidad/1411979606_979420.html

Malraux, A. (2017). El Museo Imaginario. Madrid: Cátedra.

Moreno, I. (2005). Las musas interactivas. En C. Carreras (Ed.), Patrimonio cultural y tecnologías de la información y la comunicación (pp. 95-114). Cartagena: Concejalía de Cultura de Cartagena.

Rivera, C. (2009, 13 de enero). The Official Blog for Google Maps. Madrid: Google Spain. Recuperado de: https://maps.googleblog.com/2009/01/explore-masterpieces-of-prado-museum-up.html

Santacana, J. y Hernández, F. (2006). Museología Crítica. Gijón: Trea.

Schweibenz, W. (2004). El desarrollo de los museos virtuales. Noticias del ICOM, 57 (3), 3.

Talens, S., y Hernández, J. (1997). Internet. Redes de Computadoras y Sistemas de Información. Madrid: Paraninfo.

Mckenzie, J. (1997, 16-19 de marzo). Building a Virtual Museum Community. En Bearman \& Trant (Presidencia), Museum and tech web: An international Conference, Los Ángeles, Estados Unidos. 